\title{
Immunohistochemical Detection of Bcl-2 in Kaposi's Sarcoma Lesions Varies According to Histopathologic Stage, Whereas Expression of Bcl-x and Mcl-1 Differs According to Human Immunodeficiency Virus Serologic Status of Patients
}

María-Teresa Fernández-Figueras, M.D., Lluís Puig, M.D., Angeles Fernández-Vasalo, B.Sc., Mireia Esquius, M.D., María-Angeles Montero, M.D., Aurelio Ariza, M.D.

Departments of Pathology (M-TF-F, AF-V, M-AM, AA) and Dermatology (ME), Hospital Universitari Germans Trias i Pujol, Badalona, and Department of Dermatology (LP), Hospital de la Santa Creu i Sant Pau, Barcelona, Spain

Expression of Bcl-2, Bcl-x, and Mcl-1 was immunohistochemically evaluated in 33 cases of Kaposi's sarcoma (KS) of the skin. Of these, classic KS (C-KS) accounted for 17 cases (10 in plaque stage and 7 in tumor stage) and acquired immunodeficiency syndrome-associated KS (AIDS-KS) accounted for 16 cases ( 8 in plaque stage and 8 in tumor stage). In both C-KS and AIDS-KS, Bcl-2 immunoreaction correlated with progression stage, its average score intensity being more than 2 -fold in tumors than in plaques. In contrast, Bcl-x and Mcl-1 staining intensity was unrelated to progression stage but was dependent on human immunodeficiency virus infection status. Thus, whereas Bcl-x expression was stronger in C-KS cases, Mcl-1 immunostaining was more intense in AIDS-KS instances. These findings indicate that in cutaneous KS, some Bcl-2 family proteins exhibit differential expressions that are dependent on either progression stage or human immunodeficiency virus infection status.

KEY WORDS: Acquired immunodeficiency syndrome, Apoptosis, Bcl-2, Bcl-x, Human immunodeficiency virus, Immunohistochemistry, Kaposi's sarcoma, Mcl-1.

Mod Pathol 2000;13(4):438-445

Copyright $\odot 2000$ by The United States and Canadian Academy of Pathology, Inc.

VOL. 13, NO. 4, P. 438, 2000 Printed in the U.S.A.

Date of acceptance: September 27, 1999.

Address reprint requests to: María-Teresa Fernández-Figueras, Department of Pathology, Hospital Universitari Germans Trias i Pujol, Ctra. del Canyet, s/n, 08916 Badalona, Spain.
Kaposi's sarcoma (KS) is an angioproliferative disease that has a complex pathogenesis involving a disordered cytokine network, immune alterations, and active infection with human herpesvirus 8 (HHV-8) (16). Four epidemiologic forms of KS have been described: classic form (C-KS), affecting mainly elderly men of Mediterranean origin; African-endemic $\mathrm{KS}$; immunosuppressive drug-related KS; and acquired immunodeficiency syndrome-related KS (AIDS-KS). The last one affects mainly human immunodeficiency virus (HIV)-infected homosexual men and typically is associated with an aggressive course (1). All forms of KS have the same histology, which is characterized initially by a prominent angiogenesis and subsequently by the proliferation of spindleshaped cells that are considered to be the tumor cells of KS.

The binomial (hyperplastic/neoplastic) nature of KS is one of the most fascinating features of this disease. KS seems to begin as a reactive vascular proliferation caused by an unbalanced cytokine network (1) rather than as a true neoplasm. In some cases, KS may regress, either spontaneously (coinciding with the recovery of the normal immune response [7]) or in association with pregnancy (probably the result of a modulatory effect of human chorionic gonadotropin on vascular proliferation [8]). In advanced stages, KS behaves as a multifocal neoplasm; a monoclonal origin of multicentric lesions has been demonstrated (9).

Tumor cells can evade normal control of cell growth and survival by several mechanisms, including autocrine stimulation and overexpression of proto-oncogenes that function as antagonists of apoptosis. One of the most important negative regulators of apoptosis is Bcl-2 and its related proteins (the Bcl-2 family members), the expression of 
which is regulated by cytokines and other death survival signals at different levels $(10,11)$. Previous studies have shown that the pattern of expression of Bcl-2 and its homologues Bcl- $\mathrm{x}_{\mathrm{L}}$ (10) and Mcl-1 $(12,13)$, which share a blocking cell death function, may vary with tumor progression in some neoplasms (14-18).

Recent studies have shown expression of Bcl-2 in spindle cells of KS, both in vivo (19-21) and in culture (22). Bcl-2 upregulation in KS might prolong spindle cell viability, an effect that might result in the maintenance, growth, and progression of KS when coupled with the cell proliferation stimuli provided by the synergistic action of inflammatory and angiogenic cytokines and HIV-1 Tat protein (19).

There is a consistent relationship between HHV-8 infection and KS $(2-4,23)$, but the latter does not behave like any other virus-induced malignancy (24). HHV-8 is a $\gamma$-2 herpes virus that encodes viral effectors homologous to many oncogenes with the ability to induce transformation and angiogenesis $(2,25-29)$. Some of them, such as FLICE inhibitory protein and viral Bcl-2 $(2,27,28)$, seem to be intended to evade apoptotic destruction of the infected cell. Nevertheless, the expression of some of these viral genes in tissues is extremely low and does not seem to be relevant (6). The enhancement of Bcl-2 upregulation in advanced pathologic stages of KS (19-21) and the expression of the related antiapoptotic protein Bcl- $\mathrm{x}_{\mathrm{L}}$ (30) are arguments in support of a pivotal role of the Bcl-2 family proteins in the development of KS, regardless of its epidemiologic form.

The different biologic behavior of KS according to its epidemiologic presentations might be related to the degree of the host immune response impairment and the occurrence of specific derangements of the mechanisms controlling tumor growth and development, such as cytokine/growth factor overstimulation or apoptotic cell death escape. This pathogenetic construct gains support from the demonstration of the growth-promoting role of oncostatin M (31) and HIV-1 Tat protein (32) in AIDSKS. However, the possible differences between AIDS-KS and C-KS in regard to the expression of the antiapoptotic Bcl-2 family members are as yet unexplored. Equally unknown is whether the expression of these proteins varies between KS initial stages and final tumor stages, a discrepancy to be expected in light of the likeness of initial KS to a reactive hyperproliferation and of tumor stage KS to a genuine neoplasm. To address these questions, we investigated the immunohistochemical expression of Bcl-2, Bcl-x, and Mcl-1 in the various progression stages of AIDS-KS and C-KS.

\section{MATERIALS AND METHODS}

\section{Human Tissue Samples}

Skin biopsy paraffin blocks were retrieved from the files of the Department of Pathology at the Hospital Universitari Germans Trias i Pujol, Badalona, Spain. Only cases in which immunohistochemical preservation was adequate for evaluation were included in the study. They corresponded to 33 randomly selected cases of C-KS and AIDS-KS, including 18 cases of plaque stage KS $(10 \mathrm{C}-\mathrm{KS}$ and 8 AIDS-KS) and 15 cases of tumor stage KS (7 C-KS and 8 AIDS-KS). The stage was determined by histopathologic study of hematoxylin and eosinstained sections. Patch lesions were not included in this study because it is very difficult to discriminate between tumor cells and activated endothelial cells in this stage of KS. A diagnosis of KS plaque stage was made when most of the lesion was located in the middle and superficial dermis and consisted of malformed vascular channels that dissected the collagen fibers and contained only isolated spindleshaped cells or small groups of them. A diagnosis of the nodular or tumor phase was made when the entire lesion or most of it showed a compact proliferation of spindle-shaped cells with an intersecting fascicle-like pattern alleviated only by some inflammatory cells, erythrocytes, or telangiectatic spaces. All tissue specimens had been fixed in neutral-buffered formalin for less than $24 \mathrm{~h}$ and routinely processed.

\section{Antibodies and Immunohistochemical Studies}

Immunohistochemistry was performed with the following primary antibodies: (1) mouse monoclonal antihuman Bcl-2 oncoprotein antibody (DAKO-Bcl-2 clone 124; DAKO, Glostrup, Denmark; diluted 1:20 with phosphate-buffered saline), (2) goat polyclonal antihuman Bcl- $\mathrm{x}_{\mathrm{S} / \mathrm{L}}$ (S-18)-G antibody (Santa Cruz Biotechnology, Santa Cruz, CA; diluted 1:50), and (3) polyclonal rabbit antihuman Mcl-1 antibody (Pharmingen, San Diego, CA; diluted 1:1000). For Bcl-2 and Mcl-1 detection, 5- $\mu \mathrm{m}$ sections were deparaffinized, hydrated, immersed in buffered citrate, and autoclaved. Afterward, the sections were incubated for 30 min in rabbit serum (bcl-2) or pig serum (mcl-1). Incubations with primary antibodies were carried out for $22 \mathrm{~h}$ at room temperature. Slides were washed and incubated with biotinylated rabbit antimouse IG antibodies at a 1:700 dilution and then incubated in phosphate-buffered saline $/ 6 \%$ hydrogen peroxide for $15 \mathrm{~min}$ at room temperature before avidin-biotinperoxidase complex addition (Dakopatts, Glostrup, Denmark). For Bcl-x detection, the cells were previously permeabilized with saponin and then a semiautomated system (Nexes; Ventana Medical Systems, Tucson, AZ) was used. The chromogen 3,3'- 
diaminobenzidine tetrachloride (Serva, Heidelberg, Germany) was applied, and counterstaining was performed with Harris hematoxylin. A nonimmune mouse serum was used as a negative control in this protocol. Immunohistologic procedures for each antibody were run in all specimens on the same day to minimize intersample technical variability.

Immunostaining results were scored as previously described $(14,15,33)$. The percentage of positive tumor cells was graded from 0 to 4 as follows: 0 , none to $10 \% ; 1,11$ to $33 \% ; 2,33$ to $66 \% ; 3,67$ to $90 \%$; and 4,91 to $100 \%$. Specimens were considered immunopositive when more than $10 \%$ of cells showed clear evidence of immunostaining. The intensity of immunostaining was rated as follows: 0 , none; 1 , weak; 2 , moderate; and 3 , intense. Because KS lesions frequently show significant intraspecimen heterogeneity, a score was calculated in which the percentage positive rating was multiplied by the intensity rating. In this scoring system, each component of the tumor was scored independently and the results were added up. For instance, a biopsy specimen in which $25 \%$ of cells stained intensely $(1 \times 3=3)$ and $50 \%$ had a moderate staining intensity $(2 \times 2=4)$ was assigned a global score of $3+4=7$. The reproducibility of the results was confirmed by comparison of the scores assigned by two different researchers (MTFF and LP). The score was calculated on 6 to 10 representative high-power fields after examination of the totality of tumor present in one section for each case. The smallest size of the biopsy specimens included in the study was that of a punch biopsy measuring $4 \mathrm{~mm}$ in diameter and $5 \mathrm{~mm}$ in depth. All tissue sections contained nontumor cells, such as epidermal and adnexal cells, and melanocytes, as well as arrectores pili muscles or nerves in some cases, which served as internal positive and negative controls for the assessment of antibody specificity and epitope immunopreservation. When the intensity of staining of the internal controls did not reach the expected score of 2 or 3 (depending on the cell type and location), the cases were discarded for further evaluation.

\section{Statistical Study}

Statistical significance for differences observed in the staining scores between C-KS and AIDS-KS lesions and between plaque lesions and tumor lesions was determined using analysis of variance. When variances were not homogeneous or samples were not normally distributed, the Kruskal-Wallis test was used. Differences between groups were considered to be statistically significant when the $P$ value was less than 0.05 .

\section{RESULTS}

\section{Bcl-2}

The expression of Bcl-2 by nontumor cells was intense in melanocytes and moderate in portions of the secretory coil of sweat glands. The basal layer of the epidermis exhibited some positivity, as did reactive endothelial cells of non-neoplastic vessels located in the vicinity of the lesions or in areas of inflammation. Capillary vessels and medium-sized arterioles in noninflamed areas were negative.

Even though patch (macular) stage lesions were not included in this study, some biopsy specimens of plaques or tumors contained adjacent areas of macular stage KS. In those areas, the immunostaining of neoformed vessels was negative (Fig. 1a).

Bcl-2 expression was weak in KS plaque lesions (Fig. 1b) and moderate or intense in nodular lesions (Fig. 1c). There were some variations in the intensity between adjacent cells in the same area and from one area to another, which were scored with consideration of the approximate percentages of cells corresponding to each intensity, as detailed in the "Materials and Methods" section. The results of immunostaining scores are detailed in Table 1 . The mean scores were significantly lower in plaque lesions than in tumor lesions when all cases were grouped together, irrespective of the patients' HIV serologic status $(2.8 \pm 1.6$ [mean $\pm \mathrm{SD}$ ] versus $6.2 \pm$ $2.6 ; P<.0003)$. The differences remained statistically significant when cases were stratified according to the serologic status of the patients in both AIDS-KS ( $2.6 \pm 1.8$ versus $5.6 \pm 2.8 ; P<.0262)$ and $\mathrm{C}$-KS cases $(3.0 \pm 1.6$ versus $6.9 \pm 2.3 ; P<.0031)$ (Fig. 2). In general, biopsy specimens corresponding to AIDS-KS cases seemed to exhibit a stronger staining than those corresponding to C-KS, but the differences in mean staining scores were not significant, both when all cases were grouped together and after stratification according to the type of lesion.

\section{$\mathrm{Bcl}-\mathrm{x}$}

Bcl-x staining showed a coarse, granular pattern in some cells and a fine, dustlike appearance in others. In most cases, when the cell size permitted the observation, a clear, perinuclear disposition was evident. These findings suggested an organellerelated localization. In the epidermis overlying the tumor, Bcl-x expression resulted in an intense, coarse, perinuclear granularity that in some cases was more accentuated in the upper layers and tended to disappear in the granular layer. Melanocytes, secretory cells of sweat glands, hair follicles, and arrectores pili muscles were moderately positive. Normal endothelial cells of capillary vessels and medium-sized arterioles were only occasion- 

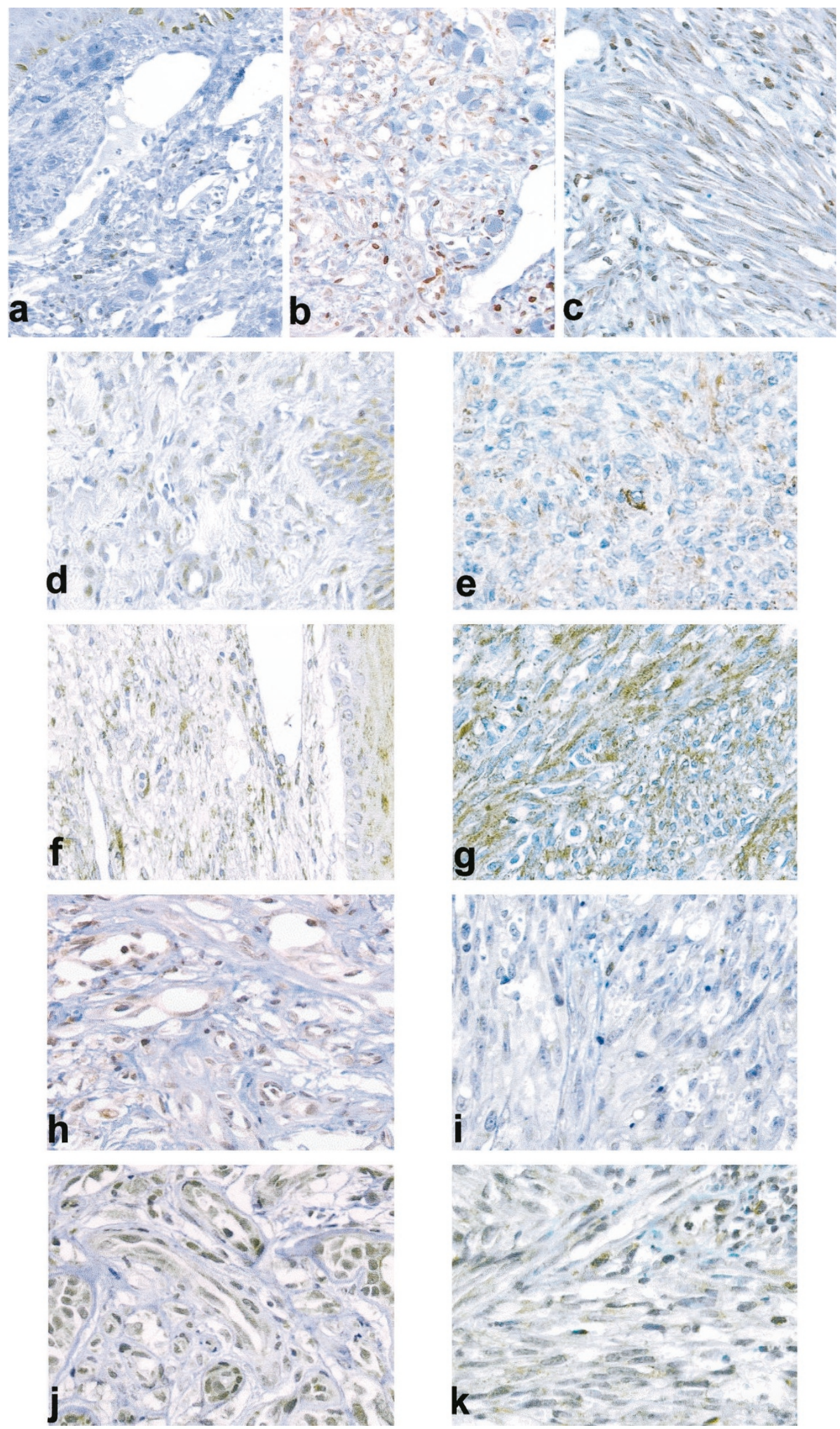

FIGURE 1. Immunohistochemical analysis of Kaposi's sarcoma (KS) lesions with Bcl-2 (a-c), Bcl-x (d-g), and Mcl-1 (h-k). Bcl-2 immunostaining was negative in macules (a) and less intense in plaque lesions (b) than in tumors (c). Intensely stained melanocytes can be seen in the epidermis (a upper left corner). The intensely stained cells that can be seen in the dermis (in a and b) correspond to lymphocytes, which also can be seen in $\mathbf{c}$. Bcl-x immunostaining was less intense in plaques (d) and tumors (e) of AIDS-associated KS than in plaques (f) and tumors (g) of classic KS. Positive Bcl-x epidermal staining can be appreciated on the right side of $\mathbf{d}$ and $\mathbf{f}$. Mcl-1 immunostaining was less intense in plaques (h) and tumors (i) of classic KS than in plaques (j) and tumors (k) of AIDS-associated KS. A positive-staining sweat gland coil is present among KS vessels. 


\begin{tabular}{|c|c|c|c|c|}
\hline & Case Number & Mcl-1 & Bcl-2 & Bcl-x \\
\hline \multicolumn{5}{|l|}{ Plaques } \\
\hline \multirow[t]{8}{*}{ AIDS-KS } & 1 & 8 & 0 & 5 \\
\hline & 2 & 6 & 2 & 6 \\
\hline & 3 & 8 & 4 & 6 \\
\hline & 4 & 9 & 5 & 7 \\
\hline & 5 & 7 & 2 & 5 \\
\hline & 6 & 11 & 5 & 7 \\
\hline & 7 & 10 & 1 & 6 \\
\hline & 8 & 7 & 2 & 6 \\
\hline \multirow[t]{10}{*}{ C-KS } & 9 & 4 & 1 & 4 \\
\hline & 10 & 6 & 4 & 5 \\
\hline & 11 & 6 & 6 & 7 \\
\hline & 12 & 5 & 3 & 7 \\
\hline & 13 & 8 & 2 & 8 \\
\hline & 14 & 5 & 3 & 8 \\
\hline & 15 & 4 & 2 & 2 \\
\hline & 16 & 10 & 2 & 5 \\
\hline & 17 & 8 & 2 & 2 \\
\hline & 18 & 8 & 5 & 5 \\
\hline \multicolumn{5}{|l|}{ Tumors } \\
\hline \multirow[t]{8}{*}{ AIDS-KS } & 19 & 4 & 4 & 12 \\
\hline & 20 & 8 & 8 & 10 \\
\hline & 21 & 8 & 5 & 5 \\
\hline & 22 & 8 & 0 & 5 \\
\hline & 23 & 6 & 6 & 7 \\
\hline & 24 & 6 & 7 & 6 \\
\hline & 25 & 8 & 6 & 9 \\
\hline & 26 & 9 & 9 & 7 \\
\hline \multirow[t]{7}{*}{ C-KS } & 27 & 6 & 5 & 7 \\
\hline & 28 & 4 & 10 & 8 \\
\hline & 29 & 7 & 6 & 6 \\
\hline & 30 & 8 & 4 & 7 \\
\hline & 31 & 4 & 7 & 8 \\
\hline & 32 & 10 & 10 & 7 \\
\hline & 33 & 3 & 6 & 7 \\
\hline
\end{tabular}

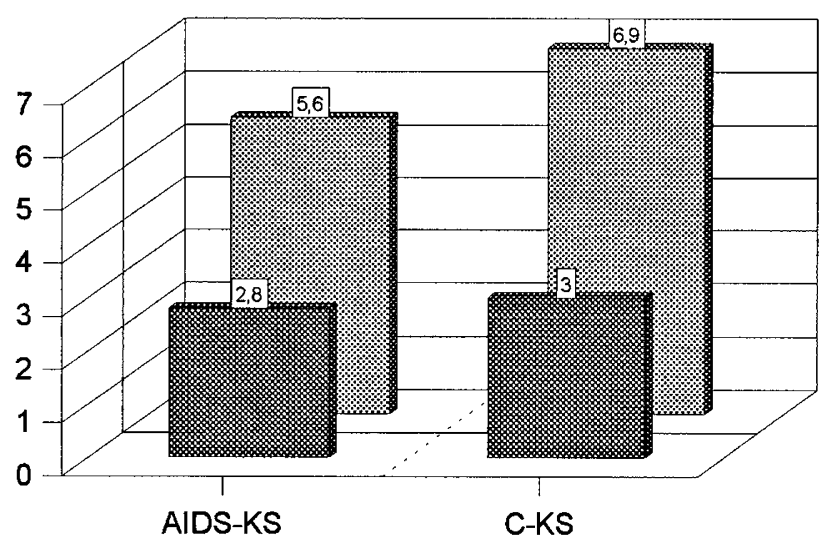

tumors plaques

FIGURE 2. Mean Bcl-2 staining scores.

ally positive, usually in relation to areas of inflammation, whereas their muscular walls displayed a moderate staining. Nerve fibers were negative or faintly positive, but a positive signal was present in some perineurial cells.

Bcl-x immunostaining was less intense in plaques (Fig. 1d) and tumors (Fig. 1e) of AIDS-KS than in plaques (Fig. 1f) and tumors (Fig. 1g) of C-KS. The mean scores of Bcl-x staining were significantly lower in AIDS-KS than in C-KS cases, both when plaques and tumors were grouped together $(6.7 \pm$ 1.9 versus $8.9 \pm 1.9 ; P<.0039)$ and when only plaque lesions were taken into consideration (6.4 \pm 1.3 versus $9.0 \pm 2.1 ; P<.0172)$. There were no significant differences in staining scores according to the type of lesions (namely, plaques versus tumors) (Fig. 3).

\section{Mcl-1}

The expression of Mcl-1 was intense in the epidermis overlying the lesions. The staining was more accentuated in the granular layer and absent in the stratum corneum. Melanocytes from the basal layer were negative or weakly positive. Hair follicles and sweat glands exhibited a weak positivity, arrectores pili muscles showed a moderate positivity, and small nerve fibers were steadily negative. These patterns of expression were similar to those previously described (13).

Within the KS lesions, the expression of Mcl-1 was moderate to intense in most cases, with a stronger expression in AIDS-KS than in C-KS cases (Figs. 1h-k). Variations in intensity and percentage of positive cells were scored, and the results are summarized in Table 1. The mean scores of Mcl-1 immunoreactivity were significantly higher in AIDS-KS than in C-KS lesions, irrespective of their type $(7.7 \pm 1.7$ versus $6.2 \pm 2.2 ; P<.0453)$. When the results were stratified according to the type of lesions (plaques or tumors), the differences between mean staining scores in AIDS-KS and C-KS cases (Fig. 4) did not reach statistical significance, even though the staining for Mcl-1 tended to be more intense in plaque lesions from patients who were HIV positive than in those corresponding to C-KS (8.2 \pm 1.7 versus $6.4 \pm 2.0 ; P=.0645$ [KruskalWallis]). There were no significant immunostaining differences between plaques and tumors, either

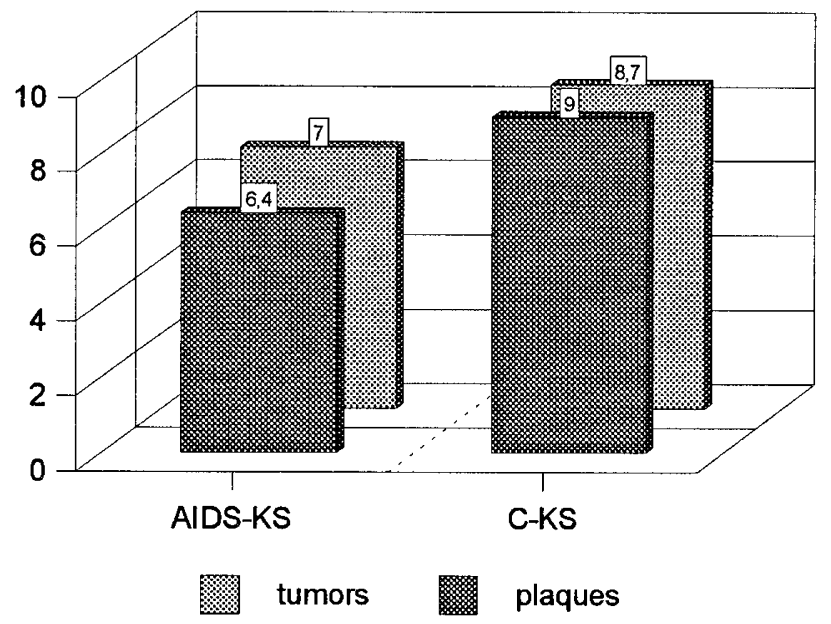

FIGURE 3. Mean Bcl-x staining scores. 


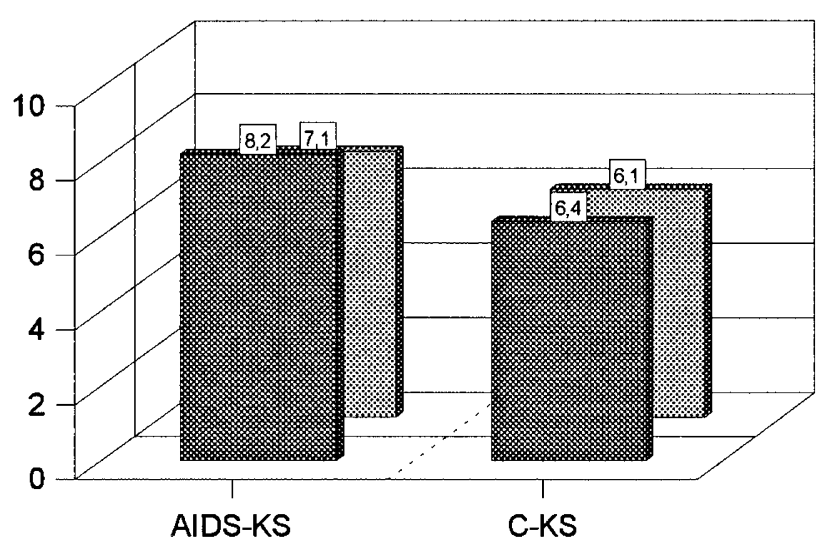

tumors plaques

FIGURE 4. Mean Mcl-1 staining scores.

when grouped together or after stratification according to HIV infection status.

In summary, the intensity of Bcl-2 staining seemed to correlate with the stage in KS lesions, the intensity being higher (more than 2-fold in average score) in tumors than in plaques. Bcl-2 staining was negative in normal endothelial cells and in newly formed vessels corresponding to areas of macular stage KS. In contrast, the mean staining intensity of the other Bcl-2 family members evaluated in this study seemed to be dependent on the presence of HIV infection. Specifically, Mcl-1 staining was more intense in AIDS-KS cases, whereas Bcl-x expression was stronger in $\mathrm{C}-\mathrm{KS}$ cases.

\section{DISCUSSION}

All of the epidemiologic forms of KS seem to be linked to HHV-8 infection (23). However, the specific role of HHV-8 in the development of KS has not yet been clearly established. It is surmised that HHV-8 may exert its effects either directly through the encoding of growth-promoting and antiapoptotic proteins or indirectly through the induction of cytokines and angiogenic protein synthesis in infected and inflammatory cells $(6,23)$. Among the latter, the most relevant are interferon- $\gamma(\gamma \mathrm{IFN})$, basic fibroblast growth factor (bFGF or FGF-2), and vascular endothelial growth factor (VEGF), which are responsible for the hyperplastic angiogenic proliferation so characteristic of the initial stages of KS and the spindle cell phenotype. Moreover, $\gamma \mathrm{IFN}$, bFGF, and other cytokines are known to influence the activity of some Bcl-2 family members $(34,35)$, thus disrupting the mechanisms that control apoptosis. Deregulation on Bcl-2-controlled apoptotic pathways is important in the pathogenesis of KS and may be one of the first steps leading to the transformation of the initial hyperplastic process into neoplasia (6).
In patients who have AIDS-KS, HIV-1 may play a role similar to or synergistic with that of HHV-8. It has been demonstrated that the HIV-1 Tat protein not only has angiogenic properties (36) but also may act synergistically with bFGF to induce KS-like lesions in mice (32). The presence of a double infection by HHV-8 and HIV-1, and a dual source of cytokines and vascular growth factors, might explain the greater incidence and aggressiveness of AIDS-KS in comparison with C-KS or with KS in patients who are HIV negative and experiencing immunosuppression. However, as stated above, differential alterations in the expression profile of Bcl-2 family members in AIDS-KS and C-KS are to be expected.

The Bcl-2 family is a group of at least 15 related cytoplasmic proteins that control an evolutionarily conserved mechanism for regulation of apoptosis. Some of the members of this family, including Bcl-2, Bcl- $\mathrm{x}_{\mathrm{L}}$, and Mcl-1, are blockers of programmed cell death, whereas others, such as Bax, $\mathrm{Bak}$, and Bcl- $\mathrm{x}_{S}$, are promoters of apoptosis (11). Cytokines and other death or survival signals modulate the expression and function of these molecules at different levels, and they can be differentially regulated in association with tumor progression and differentiation. The balance between these opposite actions is essential for normal development, protection against pathogens, and tissue homeostasis. Consequently, mutations of the genes encoding for Bcl-2 family proteins can lead to neoplasia (11).

Protecting cells from apoptosis is a function shared by Bcl-2, Bcl- $\mathrm{x}_{\mathrm{L}}$, and $\mathrm{Mcl}-1$, but they differ significantly in many regards. Bcl-2 seems to be the only family member that is susceptible to induction by bFGF (35), and its expression by KS spindle cells in vitro does not seem to be upregulated after exposure to $\gamma$ IFN (30). The angiogenic activity attributed to VEGF may be due in part to its ability to enhance endothelial cell survival by inducing expression of Bcl-2, as has been shown in human dermal microvascular endothelial cells in vitro (37).

Mcl-1 expression is induced by several cytokines, such as $\gamma$ IFN (38), granulocyte-macrophage colonystimulating factor (39), and IL6 (40), in several cell models. The intracellular distribution of Mcl-1 is essentially mitochondrial (41), being physiologically expressed in many types of long-lived cells (13) and frequently overexpressed in neoplasms. Mcl-1 expression in neoplasms does not follow an obvious pattern, so although it increases with stage or histologic grade in tumors of the thymus (18) and prostate (15) and non-Hodgkin lymphomas (17), it decreases in the more poorly differentiated neuroblastomas (14) and colorectal carcinomas (42).

Among the Bcl-2 family members, Bcl- $\mathrm{x}_{\mathrm{L}}$ is the most similar in sequence to Bcl-2. Nevertheless, 
there are considerable differences between $\mathrm{Bcl}-\mathrm{x}_{\mathrm{L}}$ and Bcl-2 in regard to their subcellular localization; relevance during embryogenesis (11); and distribution in healthy tissues, inflammation, and neoplasia $(11,14,30,34)$. The expression of Bcl- $\mathrm{x}_{\mathrm{L}}$ may be enhanced by some cytokines, including $\gamma$ IFN (30, 34) but not bFGF (35). In this study, we used an antibody directed against $\mathrm{Bcl}-\mathrm{x}_{\mathrm{S} / \mathrm{L}}$ that recognizes not only Bcl- $\mathrm{x}_{\mathrm{L}}$ but also other isoforms of this protein (including the proapoptotic $\mathrm{Bcl}-\mathrm{x}_{\mathrm{S}}$ ) that can arise through alternative mRNA splicing mechanisms. However, $\mathrm{Bcl}-\mathrm{x}_{\mathrm{S}}$ concentration in normal human tissues in vivo is extremely low (14), and $\mathrm{Bcl}-\mathrm{x}_{\mathrm{S}}$ levels are not detectable in KS-cultured cells by flow cytometric or immunoblot studies (30). Therefore, we agree with other authors $(14,15)$ in considering Bcl- $\mathrm{x}_{\mathrm{S} / \mathrm{L}}$ antibody immunostaining to be representative of the $\mathrm{Bcl}-\mathrm{x}_{\mathrm{L}}$ content of cells.

Overexpression of the apoptotic antagonists Bcl-2 $(19-22,30)$ and Bcl- $\mathrm{x}_{\mathrm{L}}$ (30) and absence of the apoptosis promoter Bax (30) have been demonstrated in KS and are considered to be important in its pathogenesis. Nevertheless, the differences in the expression of Bcl-2 family molecules among KS epidemiologic forms with different aggressive potential have never been systematically evaluated. The aim of our study was to compare the immunohistochemical expression of Bcl-2, Bcl- $\mathrm{x}_{\mathrm{L}}$, and Mcl-1 in AIDS-KS and C-KS lesions, including their variations from the plaque stage to the end tumor stage. We found statistically significant differences in the average intensity of immunohistochemical staining according to the type of lesions (progression stages) and the serologic status of the patients. The intensity of Bcl-2 staining was correlated with the progression stage in KS lesions, being more intense (more than 2-fold in average score) in tumors than in plaques. The cellular composition of lesions could explain some of the differences: Patch stage lesions of KS contain more neoplastic vessels, and tumors contain more spindle cell fascicles. The stage-related differences that we found in Bcl-2 expression can be associated with changes in both cell density and cell phenotype. Thus, the contribution of Bcl-2 overexpression to the progression of KS lesions by an antiapoptotic mechanism seems to be crucial, even though other antiapoptotic molecules and mechanisms are also involved.

In contrast to Bcl-2, the mean intensity of staining corresponding to the other members of the Bcl-2 family evaluated in this study seemed to be dependent on the presence of HIV infection. Thus, Mcl-1 staining was more intense in AIDS-KS cases, whereas Bcl-x positivity was stronger in C-KS cases. The local CD8-positive T-cell infiltration present in KS likely is accountable for $\gamma \mathrm{IFN}$ production and, consequently, induction of Bcl-x $(30,34)$ and Mcl-1
(41) (but not Bcl-2 [30]) overexpression in KS spindle cells.

It remains to be seen whether the herein identified differences in Mcl-1 and Bcl-x expression between AIDS-KS and C-KS are the result of HIV infection-related influences on cytokines and growth factors such as $\gamma$ IFN and bFGF, which provide the paracrine/autocrine stimuli leading to the development of KS. In the case of Mcl-1, it is plausible that HIV-1 Tat protein contributes to the preferential expression of this antiapoptotic molecule. Be that as it may, our findings suggest the involvement of Bcl-2 family proteins in the pathogenesis of KS, particularly in relation to histopathologic stage and HIV infection status.

Acknowledgment: This work was supported in part by grant SAF97/0220 from the Spanish Ministry of Health.

\section{REFERENCES}

1. Schwartz RA. Kaposi's sarcoma: advances and perspectives. J Am Acad Dermatol 1996;34:804-14.

2. Ganem D. KSHV and Kaposi's sarcoma: the end of the beginning? Cell 1997;91:157-60.

3. Kennedy MM, Cooper K, Howells DD, Picton S, Biddolph S, Lucas SB, et al. Identification of HHV8 in early Kaposi's sarcoma: implications for Kaposi's sarcoma pathogenesis. Mol Pathol 1998;51:14-20.

4. Brooks LA, Wilson AJ, Crook T. Kaposi's sarcoma-associated herpesvirus (KSHV)/human herpesvirus 8 (HHV8): a new human tumour virus. J Pathol 1997;182:262-5.

5. Faris M, Ensoli B, Kokot N, Nel AE. Inflammatory cytokines induce the expression of basic fibroblastic growth factor (bFGF) isoforms required for the growth of Kaposi's sarcoma and endothelial cells through the activation of AP-1 response elements in the bFGF promoter. AIDS 1998;12:19-27.

6. Fiorelli V, Gendelman R, Sirianni MC, Chang HB, Colombini $\mathrm{S}$, Markham PD, et al. $\gamma$-Interferon produced by CD8+ T cells infiltrating Kaposi's sarcoma induces spindle cells with angiogenic phenotype and synergy with human immunodeficiency virus-1 Tat protein: an immune response to human herpesvirus-8 infection? Blood 1998;91:956-67.

7. Sangiorgi G, Orlandi A, De Nardo D, Sangiorgi M, Spagnoli LG. Complete regression of iatrogenic Kaposi's sarcoma due to corticosteroid treatment in a patient with tubercular pericarditis: a case report. Annu Ital Med Int 1993;8:21-4.

8. Lunardi-Iskandar Y, Bryant JL, Zeman RA, Lam VH, Samaniego F, Besnier JM, et al. Tumorigenesis and metastasis of neoplastic Kaposi's sarcoma cell line in immunodeficient mice blocked by a human pregnancy hormone. Nature 1995; 375:64-8.

9. Rabkin CS, Janz S, Lash A, Coleman AE, Musaba E, Liotta L, et al. Monoclonal origin of multicentric Kaposi's sarcoma lesions. N Engl J Med 1997;336:988-93.

10. Reed JC. Double identity for proteins of the Bcl-2 family. Nature 1997;387:773-6.

11. Adams JM, Cory S. The Bcl-2 protein family: arbiters of cell survival. Science 1998;281:1322-6.

12. Kozopas KM, Yang T, Buchan HI, Zhou P, Craig RW. Mcl-1, a gene expressed in programmed myeloid cell differentiation, has sequence similarity to Bcl-2. Proc Natl Acad Sci U S A 1993;90:3516-20 
13. Krajewski S, Bodrug S, Krajewska M, Shabaik A, Gascoyne R, Berean $\mathrm{K}$, et al. Immunohistochemical analysis of Mcl-1 protein in human tissues: differential regulation of Mcl-1 and Bcl-2 protein suggests a unique role for Mcl-1 in control of programmed cell death in vivo. Am J Pathol 1995;146: 1309-19.

14. Krajewski S, Krajewska M, Ehrmann J, Sikorska M, Ehrmann J, Sikorska M, et al. Immunohistochemical analysis of Bcl-2, Bcl-X, Mcl-1, and Bax in tumors of central and peripheral nervous system origin. Am J Pathol 1997;150:805-14.

15. Krajewska M, Krajewski S, Epstein JI, Shabaik A, Gascoyne R, Berean K, et al. Immunohistochemical analysis of bcl-2, bax, bcl-x and mcl-1 expression in prostate cancers. Am J Pathol 1996;148:1567-76.

16. Ghia P, Boussiotis VA, Schultze JL, Cardoso AA, Dorfman DM, Gribben JG, et al. Unbalanced expression of bcl-2 family proteins in follicular lymphoma: contribution of CD40 signaling in promoting survival. Blood 1998;91:244-51.

17. Soini Y, Raunio H, Paakko P. High-grade malignant lymphomas differ from low-grade lymphomas in the extent of apoptosis and their expression of bcl-2, mcl-1, bax and p53. Tumour Biol 1998;19:176-85.

18. Chen FF, Yan JJ, Chang KC, Lai WW, Chen RM, Jin YT. Immunohistochemical localization of Mcl-1 and bcl-2 proteins in thymic epithelial tumours. Histopathology 1996;29: 541-7.

19. Morris CB, Gendelman R, Marrogi AJ, Lu M, Lockyer JM, Alperin-Lea $\mathrm{W}$, et al. Immunohistochemical detection of Bcl-2 in AIDS-associated and classical Kaposi's sarcoma. Am J Pathol 1996;148:1055-63.

20. Dada MA, Chetty R, Biddolph SC, Schneider JW, Gatter KC. The immunoexpression of Bcl-2 and p53 in Kaposi's sarcoma. Histopathology 1996;29:159-63.

21. Suster S, Fisher C, Moran C. Expression of Bcl-2 oncoprotein in benign and malignant spindle cell tumors of soft tissue, skin, serosal surfaces and gastrointestinal tract. Am J Surg Pathol 1998;22:863-72.

22. Simonart T, Degraef C, Noel JC, Fokan D, Zhou L, Pradier O, et al. Overexpression of Bcl-2 in Kaposi's sarcoma-derived cells. J Invest Dermatol 1998;349-53.

23. Boshoff C, Weiss RA. Kaposi's sarcoma associated herpesvirus. Adv Cancer Res 1998;75:57-86.

24. Boshoff C. Coupling herpesvirus to angiogenesis. Nature 1998;391:24-5.

25. Bais C, Santomasso B, Coso O, Arvanitakis L, Raaka EG, Gutkind JS, et al. G-protein coupled receptor of Kaposi's sarcoma-associated herpesvirus is a viral oncogene and angiogenesis activator. Nature 1998,391:86-9.

26. Sirianni MC, Vicenzi L, Fiorelli V, Topino S, Scala E, Uccini S, et al. $\gamma$-Interferon production in peripheral blood mononuclear cells and tumor infiltrating lymphocytes from Kaposi's sarcoma patients: correlation with the presence of human herpesvirus-8 in peripheral blood mononuclear cells and lesional macrophages. Bood 1998;91:968-76.

27. Tschopp J, Thome M, Hofmann K, Meinl E. The fight of viruses against apoptosis. Curr Opin Genet Dev 1998;8:82-7.
28. Cheng EH, Nicholas J, Bellows D, Hayward GS, Guo HG, Reitz MS, et al. A Bcl-2 homolog encoded by Kaposi's sarcoma-associated virus, human herpesvirus 8, inhibits apoptosis but does not heterodimerize with Bax or Bak. Proc Natl Acad Sci U S A 1997;94:690-4.

29. Sarid R, Sato T, Bohenzky RA, Russo JJ, Chang Y. Kaposi's sarcoma-associated herpesvirus encodes a functional bcl-2 homologue. Nat Med 1997;3:293-8.

30. Foreman KE, Wrone-Smith T, Boise LH, Thompson CB, Polverini PJ, Simonian PL, et al. Kaposi's sarcoma tumor cells preferentially express Bcl- $\mathrm{x}_{\mathrm{L}}$. Am J Pathol 1996;149:795-803.

31. Cai J, Gill PS, Masood R, Chandrasoma P, Jung B, Law RE, et al. Oncostatin-M is an autocrine growth factor in Kaposi's sarcoma. Am J Pathol 1994;145:74-9.

32. Ensoli B, Gendelman R, Markham P, Fiorelli V, Colombini S, Raffeld M, et al. Synergy between basic fibroblast growth factor and HIV-1 Tat protein in induction of Kaposi's sarcoma. Nature 1994;371:674-80.

33. Kahane H, Sharp JW, Shuman GB, Dasilva G, Epstein JI. Utilization of high molecular weight cytokeratin on prostate needle biopsies in an independent laboratory. Urology 1995; 45:981-6.

34. Wrone-Smith T, Johnson T, Nelson B, Boise LH, Thompson CB, Nunez G, et al. Discordant expression of Bcl-x and bcl-2 by keratinocytes in vitro and psoriatic keratinocytes in vivo. Am J Pathol 1995;146:1079-88.

35. Karsan A, Yee E, Poirier GG, Zhou P, Craig R, Harlan JM. Fibroblast growth factor-2 inhibits endothelial cell apoptosis by Bcl-2 dependent and independent mechanisms. Am J Pathol 1997;151:1775-84.

36. Albini A, Barillari G, Benelli R, Gallo RC, Ensoli B. Angiogenic properties of human immunodeficiency virus type 1 Tat protein. Proc Natl Acad Sci U S A 1995;92:4838-42.

37. Nör JE, Christensen J, Mooney DJ, Polverini PJ. Vascular endothelial growth factor (VEGF)-mediated angiogenesis is associated with enhanced endothelial cell survival and induction of Bcl-2 expression. Am J Pathol 1999;154:354-84.

38. Druilhe A, Arock M, Le Goff L, Petrolani M. Human eosinophils express Bcl-2 family proteins: modulation of Mcl-1 expression by IFN-gamma. Am J Respir Cell Mol Biol 1998; 18:315-22.

39. Chao JR, Wang JM, Lee SF, Peng HW, Lin YH, Chou CH. Mcl-1 is an immediate-early gene activated by the granulocyte-macrophage colony-stimulating factor (GMCSF) signaling pathway and is one component of the GMCSF viability response. Mol Cell Biol 1998;18:4883-98.

40. Altmeyer A, Simmons RC, Krajewski S, Reed JC, Bornkamm GW, Chen Kiang S. Reversal of EBV immortalization precedes apoptosis in IL-6 induced human B cell terminal differentiation. Immunity 1997;7:667-77.

41. Yang T, Kozopas KM, Craig RW. The intracellular distribution and pattern of expression of Mcl-1 overlap with, but are not identical to those of Bcl-2. J Cell Biol 1995;128:1173-84.

42. Krajewska M, Moss SF, Krajewski S, Song K, Holt PR, Reed JC. Elevated expression of Bcl-x and reduced Bak in primary colorectal adenocarcinomas. Cancer Res 1996;56:2422-7. 